\title{
Towards high-resolution fat-suppressed T1-mapping of atrial fibrosis in the left atrium: a fit-free three-point method
}

\author{
Dana C Peters ${ }^{1 *}$, Stephanie L Thorn², Alda Bregazi ${ }^{2}$, Christi Hawley ${ }^{2}$, Mitchel R Stacy ${ }^{2}$, Albert J Sinusas ${ }^{2}$ \\ From 18th Annual SCMR Scientific Sessions \\ Nice, France. 4-7 February 2015
}

\section{Background}

Atrial fibrosis identification by late gadolinium enhancement (LGE) CMR is important as a precursor to atrial fibrillation, and may impact the outcome of catheter ablation. However, the LGE enhancement in the thin atrial wall is difficult to accurately and reproducibly detect. We sought to improve identification of fibrosis through T1-mapping, generating an index of the extracellular volume fraction (ECV). In order to achieve high spatial resolution mapping for a narrow range of relevant $\mathrm{T} 1$-values $(250-500 \mathrm{~ms})$ in a feasible scan time, we applied fit-free T1-mapping with only 3 TI values (3-pt). Preliminary data measuring the ECV of normal myocardium and the aortic valves-a thin fibrotic structureare presented.

\section{Methods}

T1-mapping employed a NAV-gated, ECG-gated, fatsuppressed 3D multi-TI gradient echo sequence [1]. The method requires $2 \mathrm{RR}$ per inversion and employed TR/ $\mathrm{TE} / \Theta=4.0 \mathrm{~ms} / 1.7 \mathrm{~ms} / 15 \mathrm{deg}, 30-40$ segments per $\mathrm{RR}$ in ventricular diastole, $30 \times 24 \mathrm{~cm}$ FOV, $1.5 \times 1.5 \times 3 \mathrm{~mm}^{3}$ true spatial resolution, $\sim 12$ minutes total scan time for measurement with three TIs, assuming 50\% NAV efficiency. The T1-mapping method was targeted to postcontrast $\mathrm{T} 1$ values $(200 \mathrm{~ms}-500 \mathrm{~ms})$, with three inversion times: $\mathrm{TI}_{1}=100 \mathrm{~ms}, \mathrm{TI}_{2}=400 \mathrm{~ms}$, and $\mathrm{TI}_{3}=\infty$ (i.e. no inversion pulse), corresponding to signal intensities $S_{1}$, $\mathrm{S}_{2}$ and $\mathrm{S}_{\infty}$. The de-rectified signals were used to calculate $\mathrm{T} 1$ analytically: If $\mathrm{S}(\mathrm{TI})=\mathrm{A}+\mathrm{B} \cdot \exp (-\mathrm{TI} / \mathrm{T} 1)$ then $\mathrm{A}=\mathrm{S}_{\infty}$ and $\mathrm{T} 1=\Delta \mathrm{TI} / \log \left[\left(\mathrm{S}_{1}-\mathrm{A}\right) /\left(\mathrm{S}_{2}-\mathrm{A}\right)\right]$. Therefore, no fitting or correction factor are needed.

${ }^{1}$ Diagnostic Radiology, Yale School of Medicine, New Haven, CT, USA Full list of author information is available at the end of the article
All imaging was performed on a Siemens 1.5T (Erlangen, Germany). Phantoms with a range of T1s (200$650 \mathrm{~ms}$ ), with $\mathrm{T} 1$ measured by spin echo inversion recovery (IR), were imaged to compare the performance of our standard T1-mapping with 6 TIs $(100$ to $500 \mathrm{~ms}, \infty)$ estimated using least-squares fitting, to the fit-free $3-\mathrm{pt}$ method. T1-maps of the left atrium were also obtained in a study of Yorkshire swine $(n=5)$ one to two weeks after myocardial infarction, $\sim 30$ minutes post injection of $0.2 \mathrm{mmol} / \mathrm{kg}$ gadobutrol. Pre-contrast TIs from literature were used.

\section{Results}

Figure 1 compares the gold-standard T1s to the fit-free 3-pt method and the 6-pt method. The Bland-Altman analysis found a bias and 2SDs for the fit-free 3-pt values of $11 \pm 35 \mathrm{~ms}$, as compared with $3 \pm 17 \mathrm{~ms}$ for the 6 -pt method. Figure 2 shows T1-mapping in atria of a

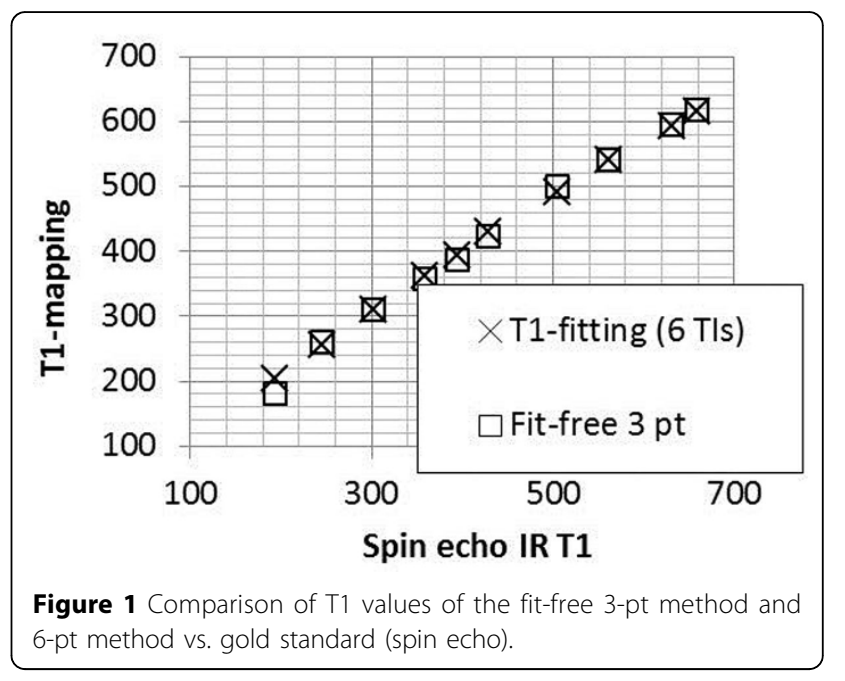



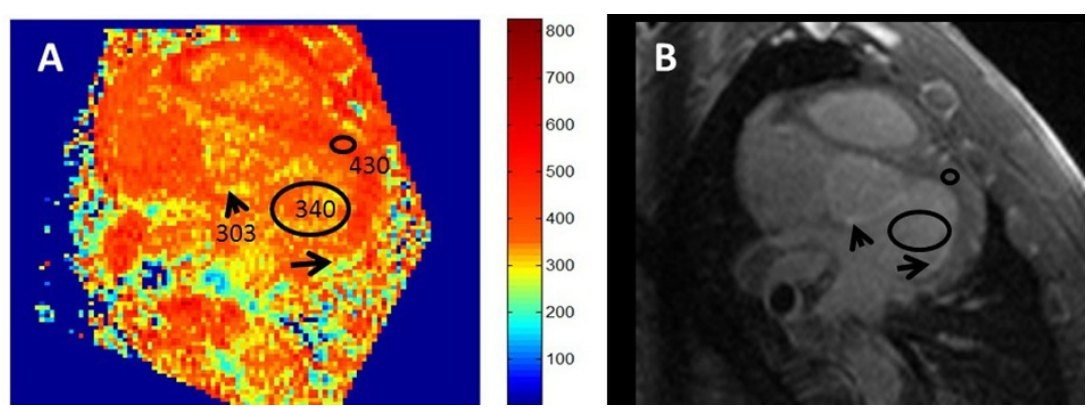

Figure 2 A) T1 map of the left atrium, showing lower $T 1$ in the valves (arrow head), which are known fibrotic structures, and in a section of the posterior LA wall (arrow). B) The Tl=400ms image highlights the identical areas. Using, pre-contrast T1s from literature, the visible LV myocardium had an estimated ECV of 29\%, and the valvular region had an ECV of 52\%, which are reasonable values for normal, and partially fibrotic structures.

swine. The average ECV values for normal myocardium $(26 \pm 3 \%)$ and the partially fibrotic valves $(49 \pm 6 \%)$ were within the expected range.

\section{Conclusions}

The 3-pt fit-free method is accurate for a narrow range of $\mathrm{T} 1 \mathrm{~s}$, in a feasible but still lengthy scan time. Future work will investigate optimization of the TI choices [2]. However, we present a step towards high resolution T1-mapping for detection of atrial fibrosis.

\section{Funding}

The authors acknowledge funding from NHLBI R01HL113352 and 1R21HL103463.

\section{Authors' details}

'Diagnostic Radiology, Yale School of Medicine, New Haven, CT, USA

${ }^{2}$ Internal Medicine, Yale School of Medicine, New Haven, CT, USA.

Published: 3 February 2015

\section{References}

1. Blume U, et al: JMRI 2009, 29:480-7.

2. Akcaya M, et al: MRM 2014

doi:10.1186/1532-429X-17-S1-W17

Cite this article as: Peters et al:: Towards high-resolution fat-suppressed T1-mapping of atrial fibrosis in the left atrium: a fit-free three-point method. Journal of Cardiovascular Magnetic Resonance 2015 17(Suppl 1): W17.

\section{Submit your next manuscript to BioMed Central} and take full advantage of:

- Convenient online submission

- Thorough peer review

- No space constraints or color figure charges

- Immediate publication on acceptance

- Inclusion in PubMed, CAS, Scopus and Google Scholar

- Research which is freely available for redistribution 